\title{
Explaining the New Street Snap Style Among Young People in China, From 2017 to 2021: Rap Shows and Celebrity Effect and Hip-hop Culture
}

\author{
Zixuan Yan $^{1, *}$ \\ ${ }^{1}$ Jinan foreign language school, Jinan, Shandong Province, China \\ *Corresponding author. Email: 20150190@stu.nun.edu.cn
}

\begin{abstract}
Why is hip-hop dominant in China's street snap from 2017 to 2021? Many friends of mine have started wearing hiphop clothes in recent years. Celebrities have also been posting pictures of themselves wearing hoodies, and other garments represent hip-hop culture on various platforms. To find out this problem, this essay used the survey method to investigate students aged between 16 and 26. The reason for adopting the survey method is that it is easy to operate, analyze the results, target a wide range of people, and the results are universal. China is taken as an example in this essay. According to the data from the survey, one of the important reasons for the popularity of hip-hop elements in China street shot is the influence of variety shows that have relativity with hip-hop launched after 2017. This result reflects valuable information. People who love hip-hop culture can have a reference to study its development in China. At the same time, it shows that the media play an important role in cultural communication. In addition, this study can help the government supervise and promote cultural development.
\end{abstract}

Keywords: Street Fashion, Hip-hop Culture, Garment, TV Shows, Celebrity.

\section{INTRODUCTION}

This topic mainly discusses that why the new trend of street shot in China around 2017-2021 is mostly hiphop style. The reason why survey this topic is that although many people write how hip-hop left a lasting influence on street fashion in a general way, this article mainly discusses the influence of street fashion trend in China.

The new trend of street shot in China around 20172021 is mostly hip-hop style. That is because a few fashions or hip-hop shows like "Rap in China" have aired around 2017, which are usually invite stars as guests.

I will look into China as a case for my research. Hiphop culture spread in China relatively late, but it is developing rapidly. According to the survey, we know that teenagers around 16 26 years old maybe admire celebrities, so they may follow the celebrities who are invited by those shows. That is shown in teenagers may imitate hip hop style clothes worn by celebrities. Then some people with a herd mentality will follow this increasingly popular style of dressing, which will lead to the influence of street fashion. Because the case is typical and can represent the phenomenon, so I choose this case.

After showing the research question, the research background, the case, readers already know what your research will be about. Therefore in the 4th paragraph, you should stress why your research matters. Do not rush here because you need to show the value and importance of your research. Take your time. Think from the pure academic perspective: will your research reveal new opinions, will your research produce and spread new knowledge, and how your research will impact the way people understand the world. Also, think more practically: will your research be helpful to provide policy recommendations to solve a real-world problem.

The whole structure of this essay is divided into four sections. Section 1 is about street fashion. In the first section, I will talk about the details of street fashion, like its history. In section2, I will discuss popular trend programs. Then the third section is about the analysis of the questionnaire survey results, and the fourth section 
is some evidence to prove the view of this paper. I will present directions for further studies in conclusion.

\section{STREET SNAP FASHION}

In recent years, many bloggers like to share their street outfits on various platforms, such as Xiaohongshu or Weibo. According to Manya Koetse, "The real street photography trend has been ongoing in China for years, near areas such as Hangzhou's Yintai shopping mall, or Chengdu's Taikoo Li. One place that is especially known for its many street photographers is Beyii andbe-seen Sanlitun area, where photographers have since long been gathc around the Apple or Uniqlo stores with their big lens cameras to capture pec by and their trendy fashion." [1]

But what if nobody is snapping your pics and you want to go viral with yours. Online influencers take matters into their own hands. They often hire their own photographer, pretend to have been caught casually, and post the video or photo on social media to go viral.

With the development of street fashion, many Internet celebrities or companies are selling clothes in this way.

\subsection{Types of Street Snap Fashion}

In China, there are different styles of a street shots. For example, Pastel Goth.

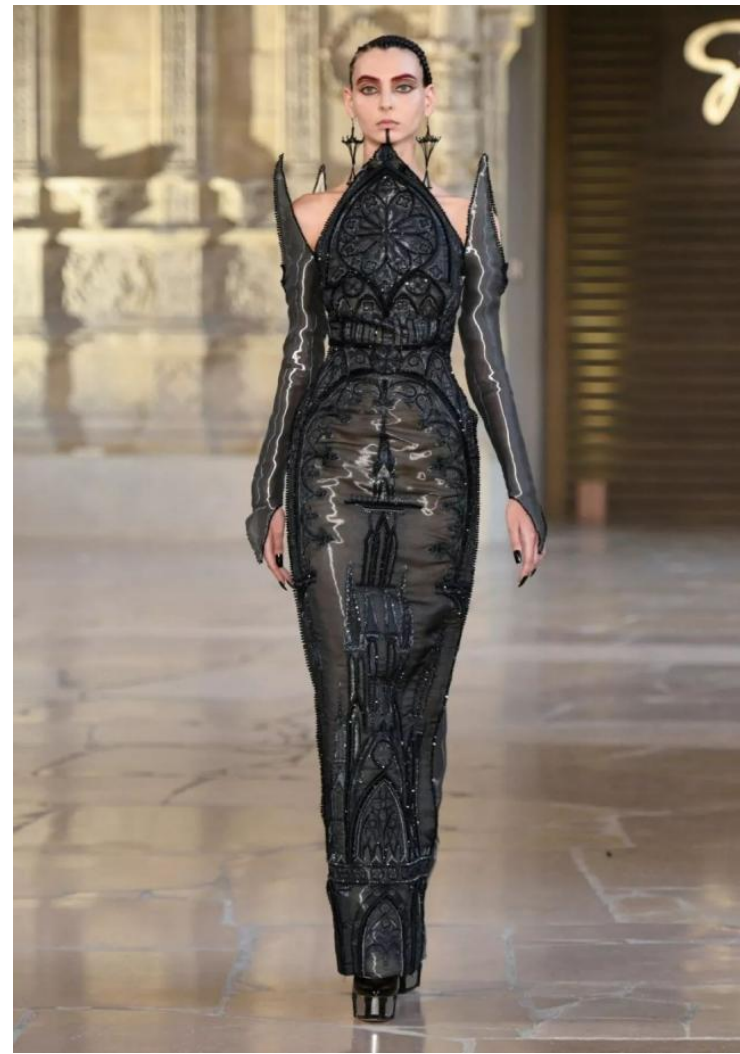

Figure 1. Goth style cloth [2]
According to Adriane: "Pastel goth is rooted in Japanese Harajuku street style and Lolita fashion. It was popular in the 2010s. Pastel goth is essentially someone saying, "Let's take goth style and make the color scheme pastel, add more cute factor, but still keep the horror elements." We also describe it as "creepy cute.”[1]

Another example is e-boy/ e-girl. E-boy and e-girl is a culture that has become popular in South Korea. According to Adriane: "The makeup of "e-people" aims to make the wearer look younger through exaggerated blush on their cheeks and nose. This look also involves dyeing hair with eccentric colors, most likely inspired by anime characters. The e- girl/boy look aims to look edgy and alternative but in a cutesy way. However, full e-girls/boys tend to be more of a persona on the internet. Rarely will you see a person on the street in full egirl/boy regalia. But these Chinese street fashionistas bring some of the most outstanding parts of this look to real life, which is what makes them so eye-catching." [1]

Traditional Chinese clothing is also an example, such as cheongsam or Hanfu.

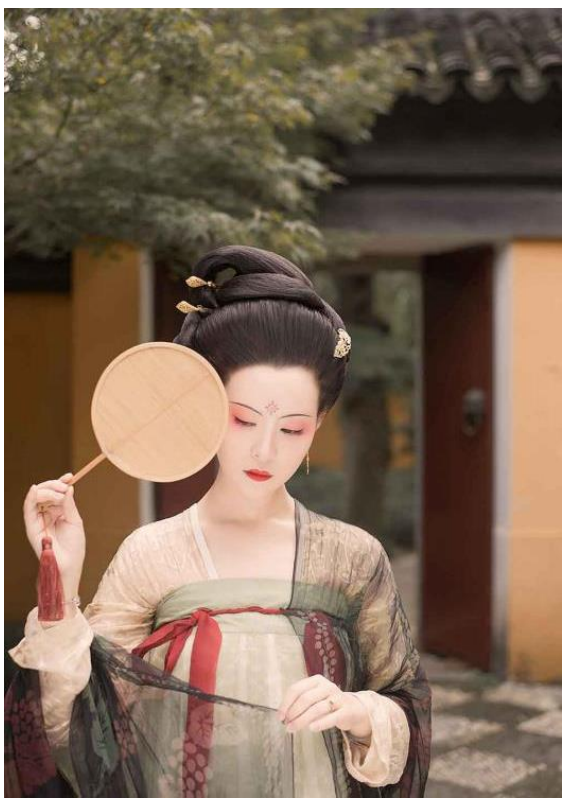

Figure 2. Chinese traditional clothing [3]

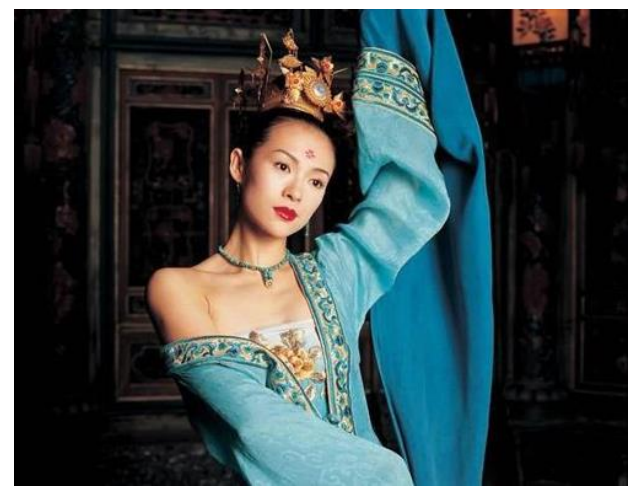

Figure 3. Chinese traditional clothing [3] 
The two photos above show dresses that use traditional Hanfu.

There is usually a gender divide between different styles of clothing. However, hip-hop style is an exception. It is generally gender-neutral.

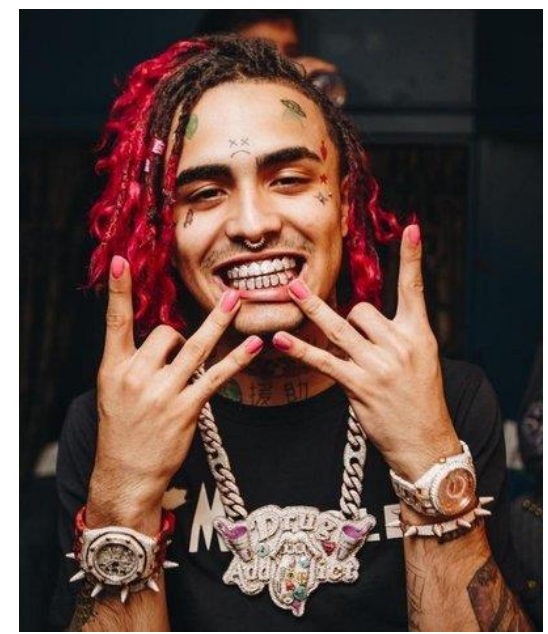

Figure 4. Hip-hop element--metal accessories [4]

According to Adriane: "Another classic look that has integrated into Chinese street style is hip-hop fashion. Hip-hop is a movement created in the 70 s by the African-American community in the Bronx, New York. While it is a highly innovative music genre, hip-hop also influenced the fashion industry. Fashion became a method of expression for artists. The hip-hop community made its own < rules, rather than follow mainstream fashion trends in the music industry." [5]

\subsection{Platforms of Street Snap Spread in China}

The popularity of hip-hop culture in China cannot be achieved without the promotion of various platforms. In fact, there is a gap in the form of these network platforms and the people who use them. As a result, equally popular platforms may have different levels of interest in spreading the same information, which results in some platforms having a lot of content related to street photos, while others have none. And this difference also leads to the same message, but the quality of publicity is different, which also means that the same thing will be in different forms between different people. On some very famous platforms, a message may get tens of millions of shares. For example, "xiaohongshu ", "Tiktok", "kuaishou", "ins" are relatively famous platforms in China. However, there are several features between them.

The users of "xiaohongshu" are mostly highly educated, so the content of their street photos is highquality and creative, and the style of clothes matching is also novel. However, Tiktok has a wide range of users, including many Internet celebrities who like to attract attention. So their street videos are more likely to mimic trends. As a result, their video quality varies, and many of them have exactly the same content and format. On platforms like "kuaishou", most of its users are people with mediocre education or aesthetic level, so videos about street snaps and clothing matching are actually relatively few, just some weird videos made by Internet celebrities.

\section{HOW HIP-HOP CULTURE BECAME POPULAR IN STREET FASHION OF CHINA}

In this section, I will discuss how hip-hop culture became popular in the street fashion of China. I will explain it from the following three aspects: economicbased explanation, the impact of TV shows and celebrities, and the influence of hip-hop culture.

\subsection{Economics-Based Explanations}

One of the reasons influencing the development of hip-hop culture may be that China's economy is getting better and better at the moment, and young people can pay for something they like even if they have no source of income. According to Marc Bain, These young people also have a lot of disposable income. One effect of China's one-child policy, which lasted from the late 1970s until 2015 (paywall), was to create many households with two parental incomes and just one child to spend it on. Add in up to four grandparents and the fact that many young Chinese don't move out of the house until they're earning enough and in a serious relationship, and the result is a generation with a lot of access to money [6].

However, the reason for this is limited because most other styles also have this reason, so this factor is not convincing enough, so this essay won't explain it too much here.

\subsection{TV Show and Celebrity Influences}

In 2017, after The rap in China and FOURTRY hiphop show aired, people have a rudimentary understanding of hip-hop. According to Marc Bain: "The show, The Rap of China, has been a phenomenal success since its June 2017 debut on IQiyi, the videostreaming platform from the Chinese search giant. In just its first month, the show racked up more than 600 million views, and each episode is widely talked about on social platforms such as Weibo.'[6] It marked a turning point for hip-hop in the world's most populous country. The genre has been building fans since the 1990s, but even so, it remains largely an underground art form. The government has been wary of it, fearing it might promote the wrong values for good communist youth. The Rap of China has put hip-hop squarely in the spotlight and brought streetwear along with it. Kris $\mathrm{Wu}$ 
and William Chan often appeared on camera after the show in popular logo hoodies and fashionable shoes to show their respect and love for hip-hop.

Many teenagers are interested in those rappers who are a little rebellious, and they love the cool feel of the rappers. Also, they respect their courage to chase their dreams. Under this circumstance, most of them want to know hip-hip deeply, so they search for the information they need to study hip-hop culture and learn about what it means to be hip hop culture.

At the same time, someone sensing a business opportunity from this. They begin promoting the garments in these shows, such as a hoodie, knitted hat, and baggy shorts on some well-known platforms like "DouYin" and "Red", then they always link stores that sell hip-hop style clothes in the end of the webpage. For example, "Reshake" and "TRVAIS SCOUT". Therefore, many international brands have left a deep impression on Chinese audiences.

After that, more and more young people notice this kind of hip-hop garments, then they are attracted to these loose and casual styles and hip-hop.

Some of them want to express their love for and heritage of hip-hop culture. One way is street snap with hip-hop style garments. After that, while this style of street snaps has attracted a lot of attention, some people have followed the trend of hip-hop style street snaps to get more flow. As a result, the hip-hop style of street snap has become the new trend, replacing the refined style of the old days.

\subsection{Hip-hop Culture}

First, I will define hip-hop culture. According to RORY, a cultural movement, hip hop is something you live shaped music styles, fashion, technology, art, entertainment, language, dance, education, politics, media, and more [8].

After given a definition, I will now explain when hip-hop culture emerged. According to RORY, Hip hop is a subculture and an art movement that emerged from the Bronx in New York City during the early 1970s [8].

Hip hop originated in New York in the early 1970s. Its development reflects the negative effects caused by the rapid development of society. Looking back at New York during this period, the city's desperation led to a rise in crime, gang violence, and poverty. From Rory: "A new era was on the rise fueled by sentiments of anger, hardship, end abandonment. However, the emerging hip-hop movement transformed despair and racial barriers into numerous creative outlets. It also became an outlet to deal with violence [8]." Later, with the development of hip hop, some styles of dance moves and rhyming melodies were created. This is a rough idea of the origin of hip-hop.
As for the underground spread of hip-hop culture in China since 2010, but according to The History of Rap in China: "By 2017, hip hop had been bubbling away on the underground level for about two decades. Yet in the summer of $2017 \mathrm{Z}$, it went mainstream almost overnight. Previously underground rappers suddenly became major stars, rap battles went viral online, and terms such as "freestyle" entered the mainstream lexicon. With a production budget of over 200 million RMB (29 million USD), Baidu-owned streaming platform iQIYI's The Rap of China (https://radiichina.com/tag/rap-of- china/) show changed the Chinese hip hop game forever [9]."

\section{RESEARCH DESIGN}

In this section, I will present the research design. I will mainly use two research methods: document analysis and survey method.

\subsection{Document Analysis}

I will define document analysis. According to Bowen, document analysis is 'a systematic procedure for reviewing or evaluating documents - both printed and electronic (computer-based and Internet-transmitted) material [10].' In this essay, my reference material is electronic.

After given a definition, I will show how to document analysis is conducted. Strauss and Corbin demonstrate that the purpose for the interpretation is 'elicit meaning, gain understanding, and develop empirical knowledge [11].' In this essay, I will analyze the document and try to understand the new street snap style.

I choose to use document analysis because document analysis has the following strength. Stake reveals that the advantage of document analysis is that it can provide 'rich descriptions of a single phenomenon, event, organisation [12].' Another strength of doing document analysis is from Denzin. He suggests that 'document analysis is often used in combination with other qualitative research methods as a means of triangulation - the combination of methodologies in studying the same phenomenon [13].'

\subsection{Survey Method}

My survey for this article was posted on June 27, 2021, and ended on June 30, 2021.

I choose to release the questionnaire in QZONE because there are many QQ users, and most of them are teenagers, which is in line with the audience of my survey questions. But when I sent out the questionnaire in QZONE, only 30 questionnaires were received by 1:30 a.m. on June 29, which is far from enough to form general data. After I got this result, I carefully considered the reasons. I eventually found out that out 
of my $200+$ friends, about a fifth of them are offline for a long time, and another quarter doesn't really read QZONE. In addition, there are also a majority of people will not go to open even they see. To solve this situation, I began to send the questionnaire to my friends who are close to me and online individually. It turned out to be very efficient. Almost all of them could reply to me within 10 minutes and send me their results within 15 minutes. Under this circumstance, I received 97 questionnaires before 6 PM.

\section{ANALYSIS}

In this section, I will present the survey result and then analyze the result in relation to the theory.

According to the economic explanation, the buying power of Chinese young people is important. In the survey, $70.3 \%$ of the respondents say that they have more than five hoodies in their wardrobe. This shows that most Chinese young people can afford to buy a number of hoodies to wear own every day. This can also be explained by the one-child policy as mentioned above.

\subsection{Rap Shows Impact}

Rap shows play an important role in the popularity of the new street snap style.

The survey results lend support to this argument. In China, the two TV shows are very popular. The first is The rap pf China (zhong guo xin shuo chang), airing from 2017, and its fourth season continued until 2020. Another famous TV show is Fourtry (chao liu he huo ren), spreading fashionable culture to the public. This has been very popular when it was aired in 2019, and its first season lasted until 2020.

According to the survey, $77.23 \%$ of the respondents have watched The rap of China. Also, $53.47 \%$ of the respondents state that they have watched the Fourtry. These data show that the two TV shows are indeed popular among the Chinese audience. So, I argue that this is one of the important reasons young people choose to buy clothes similar to those stars in the TV shows.

In addition, when asked why they bought the first hoodie, $21.78 \%$ of the respondents expressed that it because they have watched The rap of China and the Fourtry. This is direct evidence to prove the significance of TV shows in relation to the buying behavior of young Chinese people.

\subsection{Celebrity Effect}

It is worth mentioning that those celebrities in the TV shows are important to lead the social trend of this new streetwear. In The rap of China, the well-known Chinese singers and actors Kris $\mathrm{Wu}$ and William Chen are mentors of the contestants who participated in the singing competition of rap-style music. On the other hand, in the Fourtry, the idols popular in Chinese audiences, Ouyang Nana and Fan Chengcheng are special guests whose main role is to promote and sell fashionable clothes. It should be noted that most of their fashionable clothes are hip-hop style, and clothes of other styles are very scarce.

Because these celebrities are already very popular before recording the TV shows, they indeed have a large impact on the popularity of the TV shows and the hiphop clothes, which are the important elements in the TV shows. Hence, wearing hip-hop clothes gradually become the mainstream. In this way, individuals in our society are very likely to follow the mainstream and buy hip-hop clothes. According to the survey, $30.69 \%$ of the respondents believe that following the people around is their main motivation for purchasing hoodies with hiphop style.

Indeed, celebrities play a significant role in making hip-hop hoodies popular among Chines young people.

\subsection{Hip-hop Impact}

Hip-hop culture is an important element in the new street snap style.

This is obvious in the following two aspects. Firstly, in The rap of China, hip-hop is expressed through rap music and is demonstrated in the style of the clothes. Hip-hop style clothes, which are loose and suitable for leisure time, become more and more popular.

Secondly, in the Fourtry, hip-hop culture is directly shown in the certain fashionable clothed. That hip-hop clothed appeared in the TV show then became very popular for those who watch it. According to the survey, $88.12 \%$ of the respondents think that hip-hop culture has a big impact on our clothes.

To conclude, hip-hop culture is the root cause of the new street snap style. It becomes popular through highquality TV shows with the participation of famous celebrities.

\section{CONCLUSION}

The essay has four sections. These four sections have clearly described the fashion of Chinese street photography, the latest popular fashion programs, the analysis of questionnaire results, and the evidence to prove the point.

The research value of this research lies in that few people study the relationship between the development of hip-hop culture in China and street shooting fashion, so this article can help people who are interested in fashion, especially the development trend of Chinese fashion. In addition, more people can have a systematic 
understanding of hip-hop culture, which can better spread culture. In addition, through this study, we can know that communication and fashion development are inseparable. And the government can be based on this as a reference to establish new cultural publicity and protection departments to promote the development of cultural heritage.

However, this essay has several limitations. First of all, using China as an example is likely to be different from the situation of other countries because each country's background is different. The second point is that many factors may lead to the new trend of street photography in China, but the paper only describes part of them. Thirdly, due to the limitation of the title, I am personally interested in some parts of hip-hop culture, but I can't enlarge the explanation in this article. Based on the above situation, new papers can research according to these shortcomings and what they are.

\section{REFERENCES}

[1] Manya Koetse, June 25, 2019. Retrieved from: https://www.chinosity.com/2020/09/30/why-haschinese-street-fashion-become-so-popular/

[2] Goth style cloth. Retrieved from: https://image.so.com/i?q=\%E5\%93\%A5\%E7\%89 $\% \mathrm{~B} 9 \% \mathrm{E} 9 \% \mathrm{~A} 3 \% 8 \mathrm{E} \& \mathrm{src}=\mathrm{rel}$

[3] Chinese traditional clothing. Retrieved from: https://image.so.com/i?q=\%E6\%B1\%89\%E6\%9C $\% 8 \mathrm{D} \& s r c=t a b \_w w w$

[4] Hip-hop element--metal accessories. Retrieved from:
https://image.so.com/i?q=\%E5\%98\%BB\%E5\%93

$\% 88 \& \mathrm{src}=$ srp

[5] Heuritech, 2020. 'Why are streetwear brands all the hype in China?'. Retrieved from: https://www.heuritech.com/blog/articles/streetwear -brand-china-market/

[6] Marc Bain, Fashion reporter, February 20, 2018. Retrieved from: https:/qz.com/quartzy/1203743/hip-hop-in-chinais-driving-a-boom-in-streetwear/

[7] Rory PT, 2019. 'Hip Hop History: From the Street to the Mainstream'. Retrieved from: https://iconcollective.edu/hip-hop-history/

[8] Fan Shuhong, 2019. 'The History of Rap in China, Part 1: Early Roots and Iron Mics (1993-2009)'. Retrieved from: https://radiichina.com/the-historyof-rap-in-china-part-2-hip-hop-goes-mainstream2010-2019/

[9] Bowen, G. A. (2009). Document analysis as a qualitative research method. Qualitative research journal.

[10] Strauss, A., \& Corbin, J. (1998). Basics of qualitative research techniques (pp. 1-312). Thousand oaks, CA: Sage publications.

[11] Stake, R. E. (1995). The art of case study research. sage.

[12] Denzin, N. K. (2017). The research act: A theoretical introduction to sociological methods. Transaction publishers. 